http://dx.doi.org/10.1590/0370-44672020740067

\author{
Michel Melo Oliveira ${ }^{1,2}$ \\ https://orcid.org/0000-0002-4295-6479 \\ Cláudio Lúcio Lopes Pinto ${ }^{1,3}$ \\ https://orcid.org/0000-0001-9924-2824 \\ Douglas Batista Mazzinghy ${ }^{1,4}$ \\ https://orcid.org/0000-0003-2569-6932 \\ ${ }^{1}$ Universidade Federal de Minas Gerais - UFMG, \\ Departamento de Engenharia de Minas, \\ Belo Horizonte - Minas Gerais - Brasil. \\ E-mails: ${ }^{2}$ michelmelo@demin.ufmg.br, \\ ${ }^{3}$ cpinto@ufmg.br, ${ }^{4}$ dmazzinghy@demin.ufmg.br
}

\title{
Mining
}

\section{FEM-DEM simulation of Brazilian Tensile Strength (BTS) laboratory tests}

\begin{abstract}
A Brazilian Tensile Strength (BTS) laboratory test for meta-andesite was modeled using a Finite/Discrete Element Method (FDEM or FEM-DEM). These hybrid methodologies allow modeling the transition from continuous to discontinuous that happens on mechanical tests of rock samples. This article presents the calibration and the simulation of BTS tests using some parameters previously calibrated on UCS modeling of the same material. Irazu, a two-dimensional software developed by Geomechanica, was used to simulate the tests based on the tensile strength and the fracture pattern. The model shows that, in BTS test simulation, the mode II (shear) happens mainly on the rock-platen contact. The mode I (traction) rules the fractures on the BTS test as observed in laboratory tests. The model represents, with great fidelity, the results obtained in the physical test.
\end{abstract}

Keywords: Finite and Discrete Element method, FDEM, FEM-DEM, BTS, Brazilian Tensile Strength.

\section{Introduction}

The present article aims to calibrate and simulate the Brazilian Tensile Strength (BTS) laboratory tests using the hybrid numerical modeling - Finite Elements/ Discrete Element Method. Oliveira et al. (2020) performed the initial calibration of the meta-andesite geomechanical parameters and a simulation of a uniaxial compression test. Experimental tests of the indirect tensile strength (BTS) in metaandesite were made using the International Society of Rock Mechanics suggestions (ISRM, 1978). Due to the drilling equipment on site, the specimen diameter of $36 \mathrm{~mm}$ was used instead of the $54 \mathrm{~mm}$ recommended by ISRM.
Simulations were performed using the Irazu Software in order to calibrate the fracture energies of mode I, associated with traction, and mode II, referring to shear. Tatone and Grasselli (2015) suggest the steps for calibrating the energies of the two-mode fracture. The other variables of the model such as discretization element size, platen velocity, viscous damping and contact penalties are discussed by Oliveira et al. (2020) in their calibration research of the uniaxial compression test of the same material.

Although hybrid modeling is a recent methodology, some studies have been done mainly using the associa- tion of the Finite Element Method and the Discrete Element Method (FEM/ DEM). Mahabadi, et al. (2009) modeled diametral compression tests (BTS) for homogeneous and heterogeneous materials and discussed the applicability of hybrid modeling in this type of test. Using the ELFEN software, another FEM/DEM algorithm, Stefanizzi et al. (2009) modeled laboratory tests with results that corresponded to reality. Mahabadi, et al. (2010) applied a hybrid model to describe the behavior of Barre Granite and show that the modeling with the algorithm used, well represents the laboratory test. 


\section{Materials and methods}

The Geomechanica's Irazu software, used in this study, is based on the combination of finite and discrete element methods initially proposed by Munjiza, et al. (1995).

According to Mahabadi, et al. (2009) the domain of interest is subdivided into subdomains that correspond to individual particles or bodies. These subdomains are discretized into finite elements that define shape, contact between the elements and govern the

\subsection{Brazilian tensile test}

According to Berenbaum and Brodie (1959), the tensile strength of fragile materials is difficult to be predicted by the conventional test. The required specimen shape is one of the main reasons for this difficulty. The indirect tensile test also called the diametral compression test, or Brazilian tensile strength (BTS) deformability of the material.

Lisjak, et al. (2014) mentioned the potential contact between elements. To solve the contact detection problem Munjiza (2004) proposed the NBS algorithm (No Binary Search) that introduced the contact penalties.

The transition from continuous to discontinuous is defined by the onset of the fractures process. To generate the fractures, the method uses the stress-strain relationship that can be

test is a simple testing methodology and, therefore, commonly used to estimate the tensile strength of rocks (Claesson and Bohloli, 2002). The diameter of the BTS samples should be $54 \mathrm{~mm}$ and its width equal to its radius according to the suggestions of the International Society of Rock Mechanics (ISRM, 1978).

$$
\sigma_{t}=\frac{2 P}{\pi D t}
$$

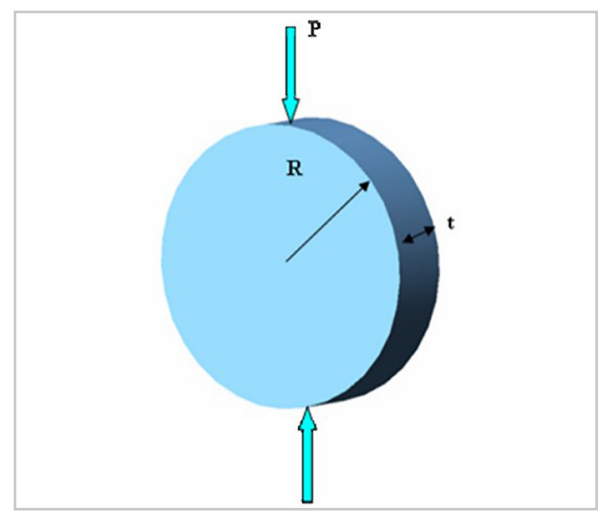

divided into two sections. The first one represents the elastic and elastoplastic behavior comprising the region between the beginning of the curve and the specimen rupture. This region is ruled by the linear elastic constitutive laws proposed by Hoek and uses the finite element method. The second section of the stress-strain curve represents the post-rupture, defined by tensions and displacements, using a simple crack model (Mahabadi, et al. 2009).

The sample is placed in a device so that the compression force is applied diametrically (Stefanizzi et al., 2009). Figure 1 shows the arrangement schematically, where $\mathrm{D}$ represents the sample diameter and $t$ its width. If $P$ is the axial force applied at the rupture, the uniaxial tensile strength can be estimated by:

Figure 1 - Brazilian Tensile Strength (Stefanizzi et al., 2009).

\subsection{Result analysis algorithm}

An algorithm provided by Geomechanica was used for analyzing the results. This Phyton language algorithm, that runs on the Paraview open-source platform, was used for the post-processing of the simulations performed in Irazu. Despite having visualization routines, the algorithm for manipulation and extraction of data from

\subsection{Model calibration}

The calibration of the model is based on the work of Tatone and Grasselli (2015). The steps for calibration of the hybrid model are: (i) definition of model element size, (ii) definition of the platen displacement velocity, (iii) definition of the Viscous Damping factor, (iv) definition of contact penalties and (v) definition of the generated files is not fully implemented in the Irazu software.

The contour condition input in the program was the platen displacement velocity. The sum of the axial nodal reaction forces is calculated at each point of the platen model, as the reaction to the platen displacement. The algorithm also calcu-

\section{fracture energies.}

The platen displacement velocity, the viscous damping factor, and the contact penalties were defined in a uniaxial compression test model discussed by Oliveira et al. (2020). The value for the platen velocity used in the simulation of the BTS was $0.03 \mathrm{~m} / \mathrm{s}$. The Viscous Damping lates the mean displacement of each node and, consequently, the displacement of each element of the model. The algorithm output file consists of 4 columns: the time interval provided by Paraview, the compression axis displacement vector in millimeters, the vector sum of the forces in $\mathrm{kN}$, and the stress calculated by Equation 1 .

$\left(1 \times 10^{6} \mu \mathrm{g} / \mathrm{mm} . \mathrm{ms}\right)$ was calculated as the critical value given by $\mu_{c}=2 \mathrm{~h} \sqrt{\rho \mathrm{E}}$, where $\mathrm{h}$ is the element size, $\rho$ is the material density and $\mathrm{E}$ is the Young's modulus of the model elements. There are other possibilities of assessing Viscous Damping in Irazu, which were not investigated in this study. The contact penalties were modeled 
in order to find the lowest standard deviation for principal stress ( $\sigma 1)$ in the uniaxial compression test (Oliveira et al. 2020). The normal and tangential contact penalties for the fracture were in the order of 100 times greater than the modulus of elasticity.

\section{Results and discussions}

\subsection{Model properties}

Figure 2 shows the ruptured specimens used in the 40 Brazilian Tensile
Strength tests. Six tests were considered invalid as the ruptures did not intersect the force application points (CP-2A, CP-3A, CP-5B, CP-12B, CP-19B, and CP-20B).

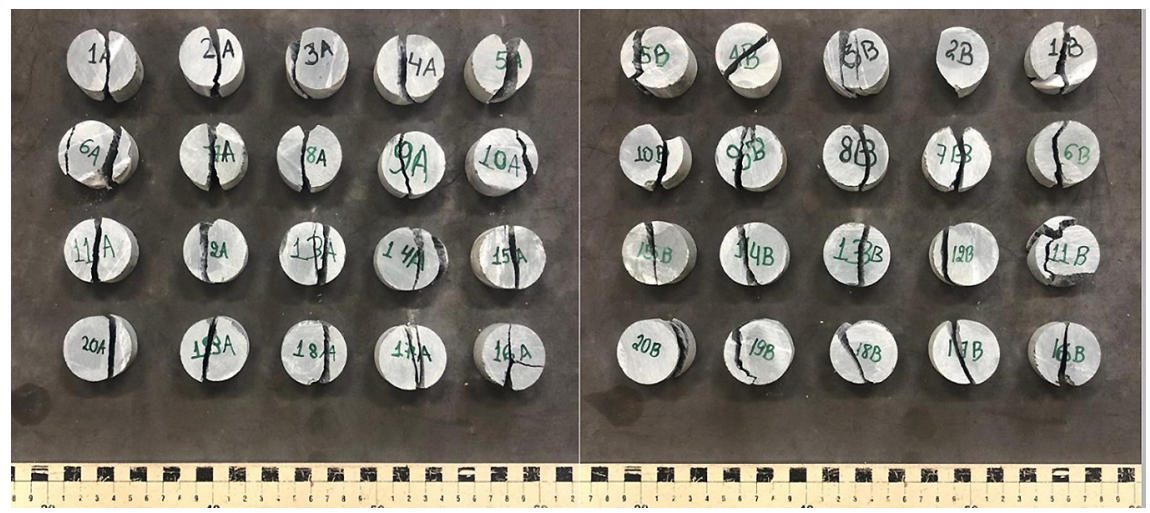

Figure 2 - Post-test meta-andesite samples (Laboratório de tecnologia de rochas (2014).

The valid values obtained show a statistical distribution close to the Gauss curve with a mean of $8.59 \mathrm{MPa}$ as shown

in the histogram shown in Figure 3.

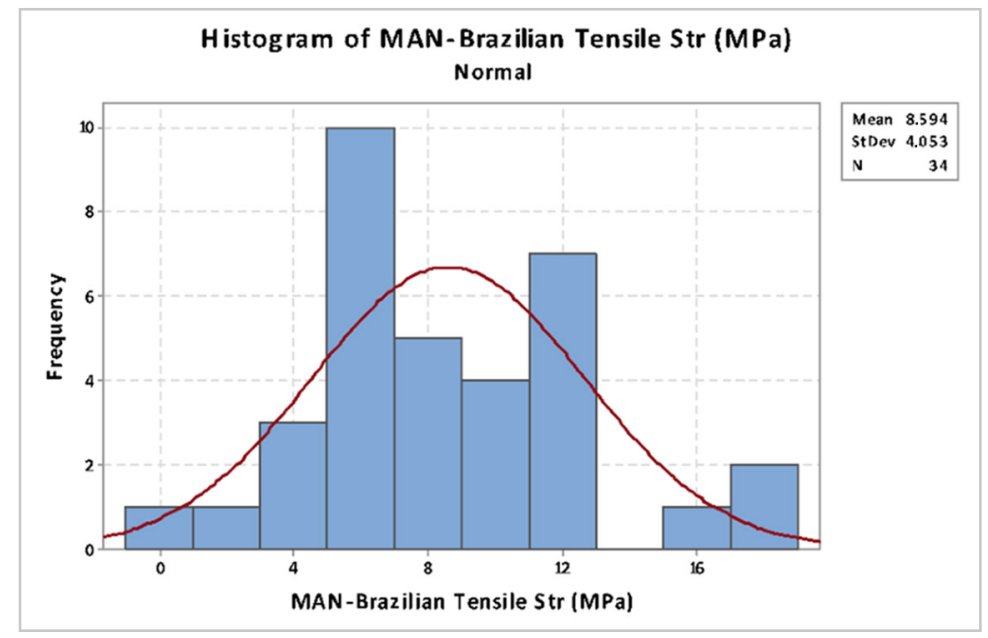

Figure 3 - Histogram of tensile strength.

The sample average diameter of $35.89 \mathrm{~mm}$, considering only the valid tests, were used for building the model. The assumed material density was $2865 \mathrm{~kg} / \mathrm{m}^{3}$ estimated by the physical property determination test. The platens, which applied the forces unto the sample, were modeled with a triangular shape (isosceles) $12 \mathrm{~mm}$ high and $37.5 \mathrm{~mm}$ wide, as the same used by Oliveira et al. (2020) in their uniaxial compression test model. Figure 4 shows the model used for the simulations.

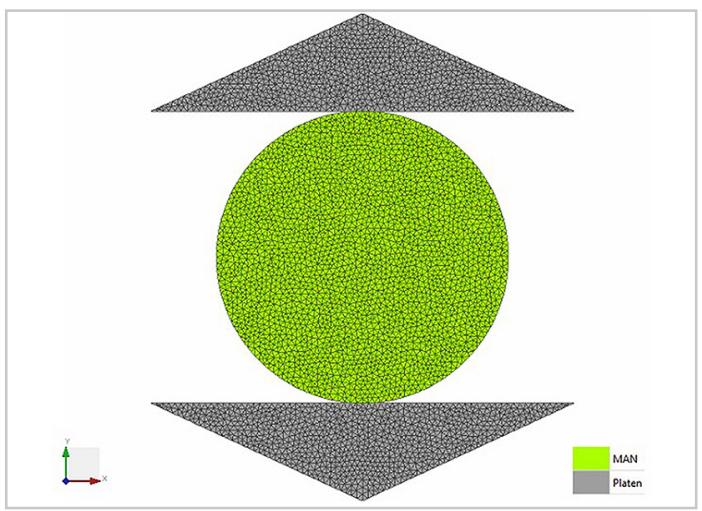

Figure 4 - Brazilian Tensile Strength Irazu model. 
Table 1 summarizes the properties of the meta-andesite and the platens which are discussed in more detail by Oliveira et al. (2020). The platen resistance was considered constant equal to $200 \mathrm{MPa}$, significantly higher than the specimen resistance. Nevertheless, all nodal points have the same constant velocity assigned as a boundary condition. Therefore, the platens can be considered infinitely rigid, non-destructible, regardless of their mechanical properties (Irazu, 2018).

The BTS model was constructed using the hypotheses of homogeneity, isotropy and under plane stress conditions. The choice of the plane stress model considers the absence of friction between the platens and the sample. The model is two-dimensional only due to the available tool.

Table 1 - Parameters used in the simulation of meta-andesite Brazilian Tensile Strength.

\begin{tabular}{c|c|c}
\hline Parameters & Rock & Platen \\
\hline Density & $2865 \mathrm{~kg} / \mathrm{m}^{3}$ & $7000 \mathrm{~kg} / \mathrm{m}^{3}$ \\
\hline Young's Modulus & $92.2 \mathrm{GPa}$ & $200 \mathrm{GPa}$ \\
\hline Poisson Ratio & 0.19 & 0.30 \\
\hline Cohesion & $30.96 \mathrm{MPa}$ & $200 \mathrm{MPa}$ \\
\hline Friction Angle & $38.23^{\circ}$ & $0^{\circ}$ \\
\hline Tensile Strenght & $8.59 \mathrm{MPa}$ & $200 \mathrm{MPa}$ \\
\hline
\end{tabular}

\subsection{Defining the size of the discretization element}

The model element size was defined using the proposal of Tatone and Grasselli (2015). Mean nominal element sizes of $0.65,0.75,0.85,0.90,1,1.5$ and
$2 \mathrm{~mm}$ were used in the simulations and the uniaxial and tensile strengths were retro analyzed, as show in Figure 5 and Figure 6 respectively. The greater the num- ber of elements, the greater the freedom for fractures process. However, the greater the number of elements in the model, the greater the computational demand.

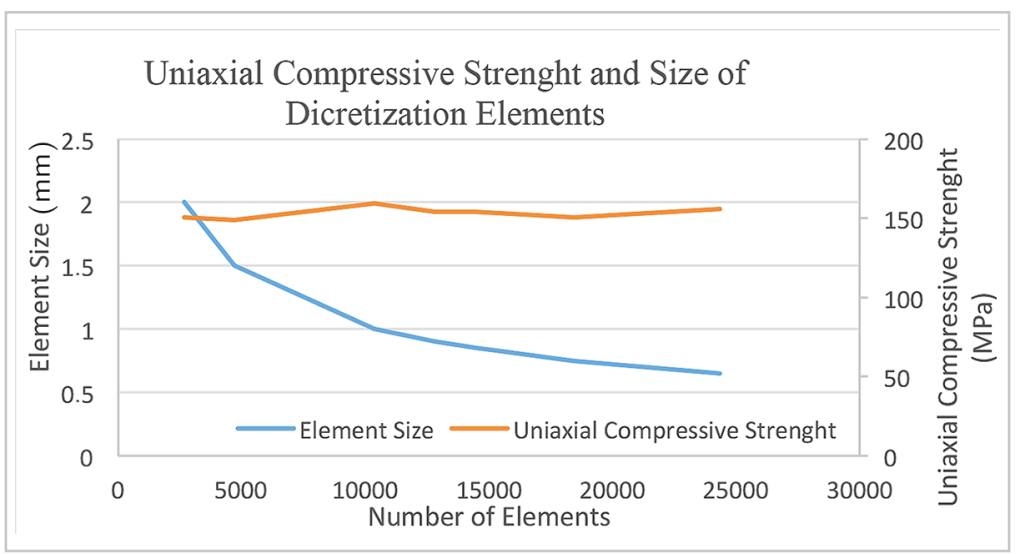

Figure 5 - Discretization size sensitivity analysis - UCS (Oliveira et. al. 2020).

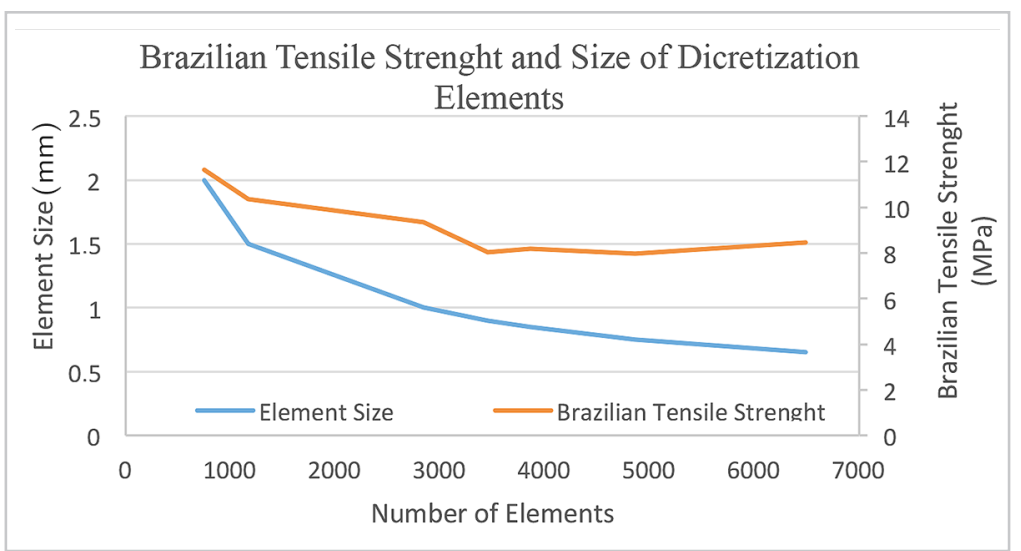

Figure 6 - Discretization size sensitivity analysis - BTS (Oliveira et. al. 2020).

In the BTS model, the tensile strength converges asymptotically to approximately $8.59 \mathrm{MPa}$ for element size of $0.75 \mathrm{~mm}$ or smaller. In the uniaxial compression test, it is not clear if there is a correlation between the size of the elements and the UCS resistance for the range of the number of elements analyzed. Therefore, the ele- ment size of $0.75 \mathrm{~mm}$ was chosen, which agrees with the work of Tatone and Grasselli (2015) and was considered for all the simulations in this study. 


\subsection{Definition of fracture energies}

The plate velocity, the viscous damping factor, and the particle contact penalties were defined using the uniaxial compression test as suggested by Tatone and Grasselli (2015). The values obtained are discussed by Oliveira et al. (2020).

The definition of the fracture energies demanded a large number of simulations, since they must be done in conjunction with the simulations of the uniaxial compression test. The software Irazu defines two fracture modes, I and II, associated with traction and shearing, respectively. Mode I (traction) has a greater influence on the tensile model, while mode II (shear) seems to have a greater influence on the uniaxial compression test, reflecting the mechanism of rupture observed in the laboratory tests. A total of 45 simulations were used to refine the values of the rupture modes suggested by the Irazu software in order to reach the values of tensile strength and compressive strength obtained in laboratories. Figure 7 shows the 3D graph of the simulation results of the Brazilian test. Successive linear regressions were carried out to define the fracture modes in each model (BTS and UCS) as suggested by Tatone and Grasselli (2015).

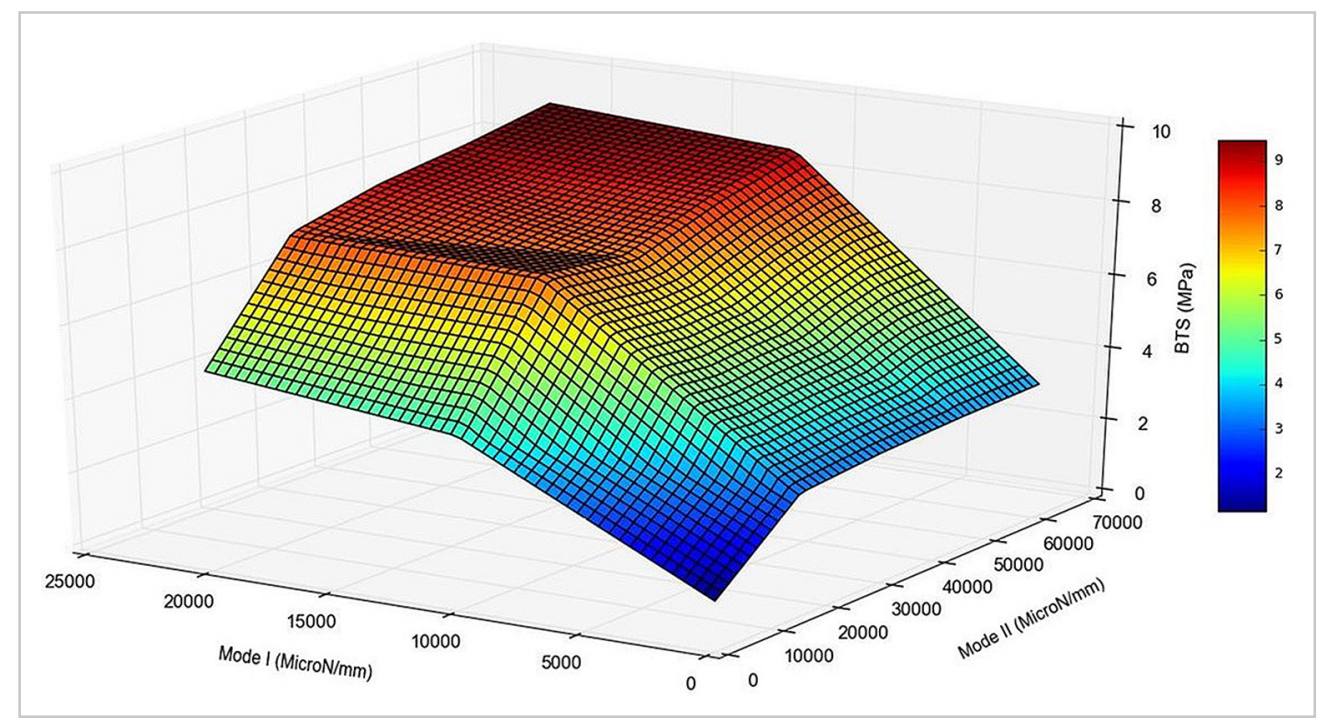

Figure 7 - Brazilian Tensile Strength (MPa) vs Mode I and Mode II Fracture Energies.

Although mode I (traction) is the main mode of rupture in the diametral compression test, the simulations show that mode II (shear) fracture energy also influences the results. Figure 8 shows the softening that takes place in the contact between the rock and the platens. The green lines dots represent the elements softening due to shear (mode II) and the gray lines represent the elements softening due to traction (mode I).

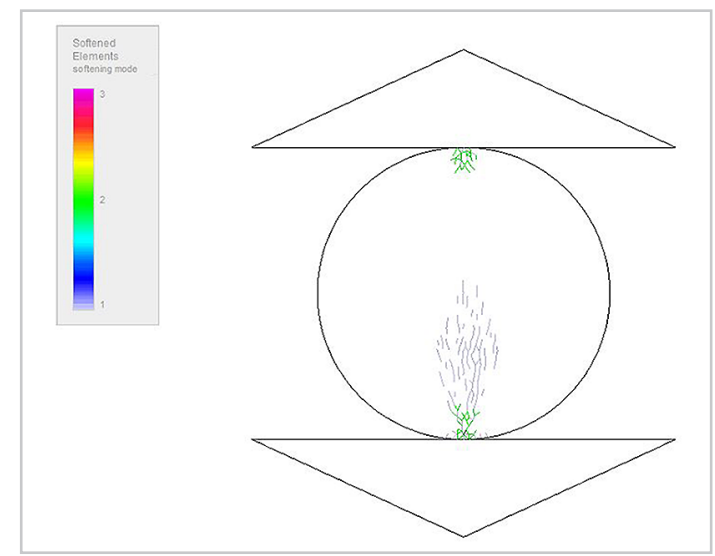

Figure 8 - Softening mode II (Shear) in the rock-platen contact.

Due to the influence of the two fracture energies in the Brazilian test, uniaxial compression simulations were carried out using the mode II (shear) value equal to $45000 \mu \mathrm{N} / \mathrm{mm}$ and varying the value of the fracture mode I (traction). Using successive linear regressions to achieve the mean diametral compression resistance obtained in the laboratory, a value of $10000 \mu \mathrm{N} / \mathrm{mm}$ was found for the
I mode (traction). The uniaxial compression model was again simulated using the mode I and mode II values of 10000 $\mu \mathrm{N} / \mathrm{mm}$ and $45000 \mu \mathrm{N} / \mathrm{mm}$, respectively reaching a UCS of $135.52 \mathrm{MPa}$.

The next step was to simulate both UCS and BTS laboratory tests varying the two fractures energy modes. The mode I (traction) of $16000 \mu \mathrm{N} /$ $\mathrm{mm}$ and mode II (shear) of $40000 \mu \mathrm{N} /$ $\mathrm{mm}$ provided the uniaxial compression strength of $134.17 \mathrm{MPa}$ and the diametral compression strength of 8.57 MPa in accordance with the laboratory resistances of $134.01 \mathrm{MPa}$ and $8.59 \mathrm{MPa}$, respectively. The mode I and mode II values are also in line with Irazu software recommendations that suggest relationships (mode I:mode II) from $1: 1$ to $1: 100$. 


\subsection{The Brazilian Tensile Strenght model}

The finite/discrete element method simulation of the laboratory Brazilian Test using the calibrated parameters can be seen in Figure 9. The model, Figure 9 a), represents the test set up, where the diameter of the specimen is

the mean diameter of the samples (valid) shown in Figure 2. Figure 9 b) shows the softening (mode II - shear) that happens in the contact between rock and platen. Figure 9 c) shows the advance of softening taking place in the center of the sample. In this instance, the mode I (traction) governs the softening process. The rupture can be seen in Figure 9 d) and corresponds to the average behavior of the ruptures observed in the laboratory (Figure 2).

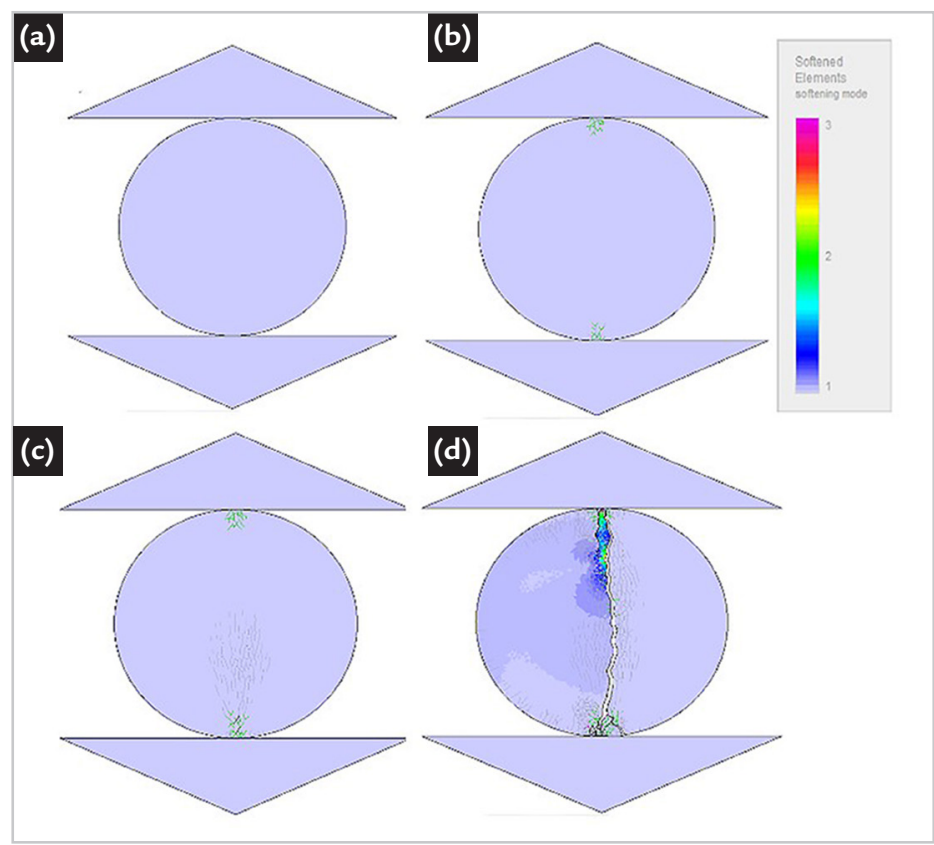

Figure 9 - Simulation of BTS a) Initial load

b) Softening mode II in contact rock-platen c) Softening Mode I in model center d) Fracture pattern.

\section{Conclusions}

The effect of discretization or the size of the element seems to be a relevant factor in the diametral compression test simulation. This phenomenon should be further analyzed, but it is probably due to the smaller number of elements. The number of elements is an important variable in defining the fracture freedom degree. The greater the number of elements, the more freely the fracture propagates. However, the higher the number of elements, the greater the computational efforts. It is suggested that the calibration of the size of the discretization elements be carried out with greater attention in the diametral tests.

\section{Acknowledgment}

The author would like to express their gratitude to all that supported this work. In
The calibration of fracture energies, mode I and mode II, requires a significantly high number of simulations. For the diametral test, the fracture mode I is the most relevant energy factor, but the results of the simulations showed that the fracture mode II also influences the estimation of tensile strength. As discussed by Oliveira et al. (2020), the mode I has practically no influence on the simulation of the uniaxial compression strength.

The values of tensile strength and uniaxial compression strength in the models with values of $16000 \mu \mathrm{N} / \mathrm{mm}$ and of $40000 \mu \mathrm{N} / \mathrm{mm}$ for mode I and mode II of fracture were $8.57 \mathrm{MPa}$ and $134.17 \mathrm{MPa}$, respectively, which is in accordance with the mean values found in the laboratory tests $(8.59 \mathrm{MPa}$ and $134 \mathrm{MPa})$.

The fracture mode II (shear) prevails in the rock-platen contact while mode I (traction) governs the fracture process in the center of the specimen. Therefore, to simulate the BTS test, it is imperative to calibrate both fracture modes simultaneously.

The simulation results point out that the hybrid (finite/discrete) model allows to simulate and to calibrate the BTS laboratory tests with great proximity to the reality.

\section{References}

special AngloGold Ashanti, CEFET-MG, PPGEM-UFMG and Geomechanica Inc.

BERENBAUM, R.; BRODIE, I. Measurement of the tensile strength of brittle materials. British Journal of Applied Physics, v. 10, p. 281-287, June 1959.

CLAESSON, J.; BOHLOLI, B. Brazilian test: stress field and tensile strength of anisotropic rocks using an analytical solution. International Journal of Rock Mechanics and Mining Sciences, v. 39, p. 991-1004, Dec. 2002.

GEOMECHANICA. Irazu 2d Tutorial Manual. [S. l.: s. n.], 2018. 
INTERNATIONAL SOCIETY FOR ROCK MECHANICS. Suggested methods for determining tensile strength of rock materials. International Journal of Rock Mechanics and Mining Sciences \& Geomechanics Abstracts, v. 15, n. 3, p. 99-103, June 1978.

LABORATÓRIO DE TECNOLOGIA DE ROCHAS. Ensaio de compressão uniaxial e triaxial. Belo Horizonte: Departamento de Engenharia de Minas - UFMG, 2014.

LISJAK, A. et al. Numerical modelling of the anisotropic mechanical behaviour of Opalinus Clay at the laboratory-scale using FEM/DEM. Rock Mechanics and Rock Engineering, v. 47, p. 187-206, 2014.

MAHABADI, O. K.; COTTRELL, B. E.; GRASSELLI, G. An example of realistic modelling of rock dynamics problems: FEM/DEM simulation of dynamic Brazilian test on barre granite. Rock Mechanics and Rock Engineering, v. 43, p. 707-716, 2010.

MAHABADI, O.; GRASSELLI, G.; MUNJIZA, A. Numerical modelling of a Brazilian disc test of layered rocks using the combined finite-discrete element method. In: CANADA-US ROCK MECHANICS SYMPOSIUM ROCKENG09, 3., 2009, Toronto. Proceedings [...]. Toronto, CA: [s. n.], 2009.

MUNJIZA, A. The combined finite-discrete element method. [S. l.]: John Wiley \& Sons, LTD, 2004.

MUNJIZA, A.; OWEN, D. R. J.; BICANIC, N. A combined finite-discrete element method in transient dynamics of fracturing solids. Engineering Computations, v. 12, n. 2, p. 145-174, Feb. 1995.

OLIVEIRA, M. M.; PINTO, C. L. L; MAZZINGHY, D. B. FEM-DEM simulation of Uniaxial Compressive Strenght (UCS) laboratory tests. REM - International Engineering Journal, v. 73, n. 4, p. 561-569, 2020.

STEFANIZZI, S. et al. Numerical modeling of standard rock mechanics laboratory tests using a finite/discrete element approach. In: CANADA-US ROCK MECHANICS SYMPOSIUM - ROCKENG09, 3., 2009, Toronto. Proceedings [...]. Toronto, CA: [s.n.], 2009.

TATONE, B. S. A.; GRASSELLI, G. A calibration procedure for two-dimensional laboratory-scale hybrid finite-discrete element simulations. International Journal of Rock Mechanics \& Mining Sciences, v. 75, p. 56-72, Apr. 2015.

Received: 25 May 2020 - Accepted: 31 May 2021. 